Finisterra, XXXVI, 72, 2001, pp. 157-178

\title{
METODOLOGIAS DE ANÁLISE E DE CLASSIFICAÇÃO DAS PAISAGENS. O exemplo do projecto Estrela
}

\author{
ANTÓNIO DE BRUM FERREIRA ${ }^{1}$ \\ Maria JoÃo AlCOFORAdO ${ }^{2}$ \\ GONÇALO TELES Vieira ${ }^{3}$ \\ CARLA MORA 4 \\ JAN JANSEN $^{5}$
}

\begin{abstract}
Resumo - Assiste-se actualmente ao renascimento dos estudos de «Ecologia da Paisagem», mas continua a verificar-se uma grande dispersão, não só nos métodos, mas também no próprio objecto e nas escalas espacial e temporal de análise. Os progressos dos métodos quantitativos e dos sistemas de informação geográfica têm conduzido muitas vezes a uma excessiva preocupação pelos padrões fisionómicos, em detrimento da dinâmica da paisagem. Por sua vez, o entendimento da paisagem como um "geossistema» tem enfrentado a dificuldade do cálculo dos fluxos de matéria e energia, que exige meios poderosos só ao alcance de alguns laboratórios. O estudo integrado do ambiente físico, mesmo num plano mais modesto, de análise mais descritiva e cartográfica do que quantitativa, exige uma investigação pluridisciplinar, defendida por muitos mas raramente posta em prática. O projecto de investigação ESTRELA tem como objectivo o estudo das relações entre a fisionomia e a dinâmica da paisagem, num ambiente de montanha, através da análise geomorfológica, climatológica e da vegetação, utilizando três escalas espaciais de análise. Referem-se os trabalhos efectuados em cada um desses domínios, dá-se um exemplo de tentativa de integração de pesquisas sectoriais e remata-se com uma perspectiva temporal da transformação da paisagem na Serra da Estrela. Um dos problemas ainda não resolvidos consiste nos critérios a adoptar na definição das unidades de paisagem.
\end{abstract}

Palavras-chave: Conceito de paisagem; estrutura e dinâmica da paisagem; projecto ESTRELA.

1 Investigador do Centro de Estudos Geográficos e Professor Catedrático da Universidade de Lisboa.

2 Investigadora do Centro de Estudos Geográficos e Professora Associada da Universidade de Lisboa. E-mail: mjalcoforado@mail.telepac.pt

3 Investigador do Centro de Estudos Geográficos e Assistente da Universidade de Lisboa. E-mail: gtvieira@ceg.ul.pt

4 Investigadora do Centro de Estudos Geográficos, Universidade de Lisboa. E-mail: cmora@ceg.ul.pt

5 Department of Ecology, University of Nijmegen, Toernooiveld, 6525 ED Nijmegen, The Netherlands. 


\begin{abstract}
Landscape Analysis and Classification Methodologies. The Example of the Estrela Project. Landscape ecology studies experience at the moment an increase of interest by researchers, developers and end-users. However, the subject matter is still too dispersed, not only in methods used but also in objects of analysis as well as space and time-scales. Progress on quantitative methods and the use of Geographical Information Systems frequently lead to excessive emphasis on physiognomic patterns to the detriment of landscape dynamics. Furthermore, the study of landscape as a geosystem suffers from problems related to calculation of mass and energy fluxes, which are barely possible, even with the powerful and costly equipment available only in few laboratories. The integrated environmental research, albeit at a more modest level, requires a multidisciplinary approach (defended by many, but seldom applied). The objective of the ESTRELA Project is to study the relations between the physiognomy and dynamics of the landscape in a mountain environment. Geomorphology, climate and vegetation are analysed at three spatial scales. The research carried out on each domain is presented and an example is given of their integration in a sample-site. The conclusion refers to the temporal transformations of the landscape of the Serra da Estrela. The problem of landscape units definition is still under investigation.
\end{abstract}

Key-words: landscape, landscape structure, landscape dynamics, ESTRELA Project.

\title{
I. DEFINIÇÃO DE PAISAGEM
}

Paisagem é mais uma palavra do que um conceito. Ou, dito de outra forma, é uma palavra com vários conceitos. No sentido mais comum do termo, aquele que figura em primeiro lugar nos dicionários, paisagem é uma extensão de terras ou uma porção de território, que se pode apreender por um golpe de vista. Mas o conceito pode ser mais amplo, incluindo, além dos aspectos visíveis, cheiros e sons. E assim é: uma charneca mediterrânea na Primavera tem sons e cheiros característicos, que a identificam. Mas a palavra paisagem pode ser encarada também num sentido figurado, podendo falar-se em paisagem política, paisagem intelectual, por exemplo.

No campo da geografia, nomeadamente da geografia física, têm sido privilegiados os aspectos mais concretos da paisagem, ou melhor, a "paisagem real», o «espaço-objecto», no sentido de «extensão cartesiana» (RIMBERT, 1973). Para esta autora, no entanto, "a noção de paisagem depende, antes do mais, da maneira de a observar, isto é, de apreender o espaço terrestre», ou seja, a «imagem mental da paisagem». Acentua mesmo que «apenas as paisagens subjectivas têm um impacto afectivo capaz de orientar as decisões dos indivíduos e dos grupos» (ob. cit, pp. 234-235).

Sem de modo algum desmerecer esta última noção de paisagem, é a «paisagem real» que nos vai ocupar neste trabalho. Como diz RougERIE (1969, p. 5), logo na primeira frase da sua «Geografia das paisagens», «é cómodo definir a geografia como o estudo das paisagens» e acrescenta: «na medida em que a geografia consiste em localizar os factos, apreender as diferenciações 
do espaço terrestre e a comparar os conjuntos, detectando o seu dinamismo interno e as suas relações recíprocas, é estar bem no centro desta ciência o dedicar-se à expressão material dessas diferenciações: as paisagens».

O certo é que a paisagem, como objecto de estudo científico, embora seja uma preocupação antiga, nomeadamente da geografia física e de outras ciências da Terra, não mereceu uma atenção continuada, e ainda hoje não se pode falar propriamente de uma "ciência da paisagem», com objecto e métodos bem definidos. Assiste-se, isso sim, a um interesse renovado pelos estudos da paisagem, ou simplesmente pela paisagem como objecto de consumo. As publicações abundam e multiplicam-se, mas a paisagem é entendida com significados muito diversos e analisada por vezes sem qualquer rigor científico.

Um domínio de estudo da paisagem, que tende a desenvolver-se, é a chamada «Ecologia da Paisagem». A designação deve-se a Troll (1939), para a qual propôs mais tarde o nome de "Geoecologia» (Troll, 1971), e era entendida como o estudo das inter-relações dos elementos físicos da paisagem. Tratava-se, no entanto, de uma análise essencialmente qualitativa, fisionómica e cartográfica, como sublinha Sala (1982/83). As análises da «ecologia da paisagem» foram-se enriquecendo, em relação aos estudos iniciais da escola de Troll, com o desenvolvimento, por um lado, da geomorfologia dinâmica e, por outro, dos estudos da botânica e da fitossociologia. Geomorfologia e vegetação foram sempre considerados dois constituintes fundamentais das paisagens terrestres; mas inicialmente eram tomados apenas os aspectos fisionómicos, em detrimento da dinâmica e das interacções.

O estudo dos espaços naturais ou pouco modificados pela intervenção humana recebeu também o contributo de um método de levantamento cartográfico conhecido por «Land Systems». O método foi desenvolvido pela «Commonwealth Scientific and Industrial Research Organisation» a partir de 1945, na Austrália. Com base esssencialmente na fotointerpretação, o objectivo era individualizar áreas homogéneas do território, caracterizadas pela sua unidade fisionómica, o que permitia uma expedita avaliação das potencialidades de utilização de terras imensas e pouco conhecidas. Esta metodologia implicava, no entanto, um "postulado inicial, o da perfeita coincidência, em toda a parte, dos limites da geomorfologia, dos solos, das unidades geológicas, fitogeográficas, etc., o que é um engano. O verdadeiro problema, tão importante no plano científico como no plano prático, é o da sua não-coincidência» (TRICART, 1994, p. 13).

\section{A PAISAGEM COMO GEOSSISTEMA}

A fisionomia de uma paisagem caracteriza-se por uma determinada estrutura, isto é, pela repetição de manchas, mosaicos, corredores e limites, que adquirem formas diversas. As fotografias aéreas, primeiro, e as imagens de satélite, depois, estiveram na base de avanços muito significativos registados 
na análise da estrutura da paisagem. Os progressos da análise quantitativa e a utilização dos sistemas de informação geográfica têm permitido refinar o estudo dos padrões fisionómicos da paisagem. Todavia, levada ao extremo, esta análise, que se exprime por índices por vezes complicados, pode revelar-se estéril ou pouco útil, se for feita sem qualquer contacto com a "paisagem real». Lembremos, a título de exemplo, o que se verificou com a análise das redes de drenagem: depois do trabalho fundamental de HorTON (1945), que se pode considerar um dos precursores da geomorfologia quantitativa, certas escolas, ou pelo menos certos investigadores, passaram a ter como objecto de análise, não os rios, mas as «linhas de água», desenhadas no mapa.

Por isso, a ecologia da paisagem não pode contentar-se com a análise pura e simples da estrutura, mas deverá procurar as causas e os próprios efeitos do padrão espacial da fisionomia das paisagens. TURNER (1989), citada por HugGetT (1995, p. 15), insiste sobre vários aspectos a ter em consideração no estudo dos «sistemas da paisagem», nomeadamente: 1) investigar «a evolução e a dinâmica da heterogeneidade espacial», isto é, tentar saber "como o mosaico da paisagem se origina e evolui»; 2) procurar «as interacções entre as paisagens heterogéneas e as trocas que se verificam entre elas», ou seja, o modo "como os materiais e os organismos se deslocam de uma mancha para outra»; 3) elucidar "a influência que a própria heterogeneidade do mosaico da paisagem exerce sobre os processos bióticos e abióticos da paisagem».

Assim, deveria considerar-se a paisagem como um "geossistema», um sistema dinâmico com trocas de massa e energia com o exterior. Um "geossistema", termo utilizado pela primeira vez em 1960 pelo investigador russo Sochava, pode caracterizar-se do seguinte modo (BEROUTCHACHVILI e BERTRAND, 1978, pp. 171-172): uma morfologia, que corresponde à estrutura espacial, tanto no sentido vertical (os geohorizontes), como no sentido horizontal (expressa pelos geofácies); um funcionamento, que representa as trocas de energia e de massa com o exterior do sistema; um comportamento, que significa as mudanças de estado do sistema, em função do tempo. O geossistema diferencia-se do ecossistema porque este privilegia as biocenoses, enquanto no geossistema não há a priori tratamento preferencial entre o biótico e o abiótico. Outro aspecto a sublinhar: o papel desempenhado pelas sociedades na modificação do quadro natural. Por isso, o geossistema integra três tipos de componentes: abióticas, bióticas e antrópicas.

Huggett (1995), em vez de geossistema, prefere falar de "geoecossistema». A ideia é (tal como na definição, aliás, de geossistema) a de repor a importância dos componentes abióticos da paisagem, uma vez que os ecologistas tendem a privilegiar claramente os aspectos bióticos. Com base na definição apresentada por FORMAN e GODRON (1986), para o termo "paisagem», o geoecossistema é considerado como uma porção de espaço heterogéneo, constituído por vários ecossistemas que interagem entre si. Os elementos do geoecossistema, ou unidades de paisagem (entre outras designações igualmente possíveis), integram «as relações entre geologia, solos e vegetação» e podem ser definidos como «a mais pequena unidade homogénea visível na paisagem» (ob. cit., p.16). 


\section{O PROBLEMA DA CLASSIFICAÇÃO DA PAISAGEM}

É muito difícil propor uma classificação objectiva e universal das paisagens da Terra. Qualquer tentativa de sistematização nesta matéria terá de ter em conta as escalas espacial e temporal dos fenómenos. Uma mudança de escala espacial é acompanhada por uma mudança na natureza dos fenómenos físicos que são apreendidos, e estes por sua vez evoluem a ritmos variados, sendo por isso necessário introduzir o factor tempo.

BERTRAND (1968) propôs uma classificação corológica da paisagem, sendo as seguintes as unidades escolhidas, da mais extensa para a mais restrita: zona, domínio, região natural, geossistema, geofácies, geótopo. Esta tentativa de sistematização inspira-se, sobretudo para as unidades mais vastas, na geografia regional clássica, da escola francesa, e beneficia também da classificação espácio-temporal dos factos geomorfológicos proposta por CAILLEUX e TRICART (1956). Segundo Bertrand, a unidade mais importante da classificação da paisagem é o geossistema, porque é nele que melhor se observam as interdependências dos vários fenómenos físicos. O geossistema seria, no dizer de RichARD (1975, pp. 87-88), que retomou a classificação de Bertrand, «a unidade de interpretação do espaço geográfico», enquanto os geofácies, que compõem o geossistema, corresponderiam «à mais pequena unidade espacial homogénea», e constituiriam, por isso, "a unidade de descrição do espaço geográfico». Os geofácies teriam uma "natureza essencialmente fisionómica», sendo a formação vegetal o seu "carácter mais significativo». As escalas cartográficas da representação dos geofácies seriam 1:5.000 ou 1:10.000.

No entanto, nos trabalhos de Bertrand e seus colaboradores (BERTRAND, 1968, 1972; Carcenac-Suffert, 1978; Hérail e Hubschman, 1978; Bertrand e BERTRAND, 1986), o geossistema não é encarado verdadeiramente como um sistema dinâmico (o que, aliás, se compreende, dadas as dificuldades de medição dos fluxos de matéria e energia) mas essencialmente como uma «unidade territorial», que constitui a base das representações cartográficas apresentadas (e que podem ir da escala de 1:20.000 à escala de 1:200.000). Por outro lado, apesar de Bertrand e seus colaboradores sublinharem que os geossistemas não são simples fitogeografia, a verdade é que o essencial da terminologia adoptada e dos conteúdos da cartografia dos geossistemas se referem a formações vegetais, mais ou menos influenciadas pela intervenção humana.

Verifica-se assim nos trabalhos inspirados por Bertrand o mesmo problema encontrado nos estudos de "ecologia da paisagem», os quais tendem a privilegiar a análise da vegetação, em detrimento dos outros aspectos do ambiente físico. Pelo contrário, a "geoecologia» da escola alemã, sobretudo a partir dos anos setenta, passou a atribuir um papel importante aos processos erosivos e à sua quantificação, isto é, à geomorfologia dinâmica (Sala, 1982/83). Esta nova orientação da geomorfologia, iniciada nos princípios dos anos cinquenta nos Estados Unidos (STRAHLER, 1952; 1992) como contrapartida da perspectiva genético-evolutiva de Davis, acabou por influenciar as investigações em diversos 
países europeus. O principal aspecto inovador consistiu nas medições da erosão em parcelas experimentais ou em pequenas bacias fluviais, tentando-se depois uma generalização a espaços mais vastos. Mesmo no Reino Unido e na França, onde a geomorfologia davisiana persistiu até mais tarde, a análise e quantificação dos processos erosivos acabou por ganhar os seus adeptos.

Se há dúvidas quanto à dimensão espacial das unidades de paisagem e dificuldades no estudo do seu funcionamento numa determinada porção de espaço, mais dífícil talvez se torna procurar definir e sistematizar os ritmos da sua evolução, ou seja a sua dimensão temporal. No caso da geomorfologia, a proposta de CAILleuX e TRICART (1956) mostra como as escalas espacial e temporal estão interligadas, pois as formas de maior dimensão são também aquelas que evoluem a um ritmo mais lento. No entanto, persiste o problema de saber como conciliar um evolução de tempo longo, à escala geológica, com uma evolução de tempo curto, que é o da dinâmica geomorfológica.

\section{O PROJECTO ESTRELA: OBJECTIVOS E METODOLOGIA}

Para além das dificuldades e desencontros de linguagem e de metodologia dos estudos da paisagem natural ou pouco modificada pela intervenção humana, existe um problema de base, que é o da investigação intra e interdisciplinar, aplicada ao estudo integrado do ambiente físico. Esse tipo de investigação é muitas vezes defendido mas raramente posto em prática.

Um dos objectivos do projecto ESTRELA é o de contribuir, num ambiente de montanha, para a definição de «unidades de paisagem», que tenha em conta não só os aspectos fisionómicos da paisagem mas também a dinâmica actual e passada do ambiente físico. As paisagens actuais do planalto superior da Serra da Estrela e dos vales periféricos (fig. 1) estão profundamente marcadas pelas dinâmicas glaciária e periglaciária do Plistocénico Superior (DAVEAU, 1971), as quais perduraram na Serra da Estrela até ao final do Tardiglaciário (VIEIRA et al., 2001b). As formas e os depósitos originados nesse ambiente climático frio do Quaternário condicionam muitos aspectos da dinâmica geomorfológica actual e também do revestimento vegetal. Esta perspectiva temporal da transformação da paisagem é um tema importante mas que não é fácil de resolver, devido sobretudo às dificuldades de estabelecimento de uma cronologia absoluta das manifestações ainda hoje observáveis. No âmbito do Projecto ESTRELA, as relações entre a estrutura e a dinâmica da paisagem são analisadas na confluência da análise geomorfológica, climatológica e da vegetação, tal como se esquematiza na figura 2.

\section{A análise geomorfológica}

A análise geomorfológica segue duas vias complementares: por uma lado a cartografia geomorfológica de pormenor; por outro, a monitorização da dinâmica geomorfológica actual. 


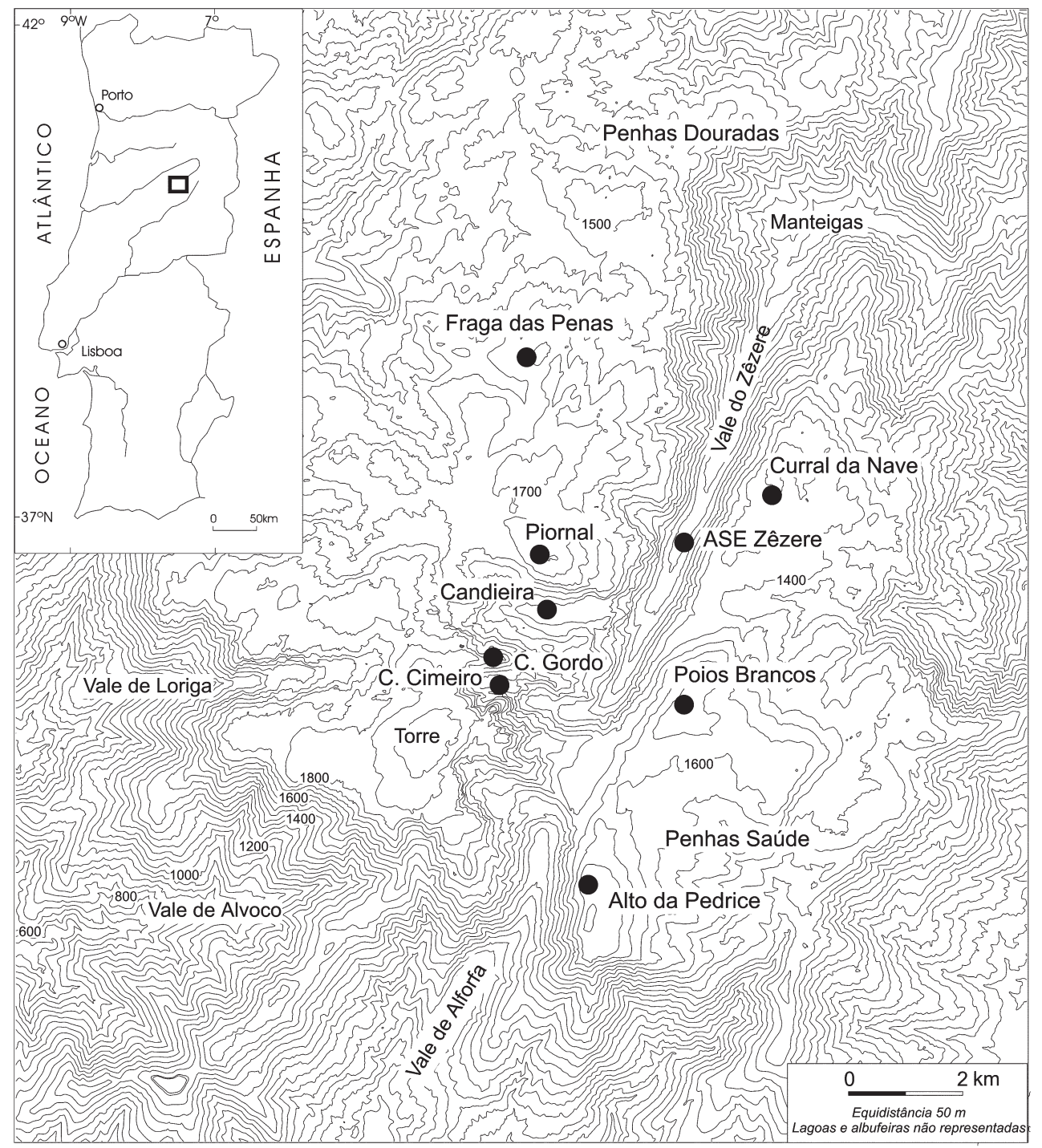

Fig. 1 - Localização da área de trabalho e dos registadores termométricos.

Fig. 1 - Study area and location of the temperature data loggers.

No que se refere à cartografia, a metodologia seguida no âmbito do presente projecto resulta da integração da cartografia geomorfológica tradicional, baseada essencialmente num trabalho de campo sistemático, na análise de fotografias aéreas de grande escala e na cartografia assistida por computador. Os levantamentos de campo foram efectuados nas escalas de 1:5.000, 1:10.000 e 1:25.000, dependendo da disponibilidade das bases topográficas e do grau de 


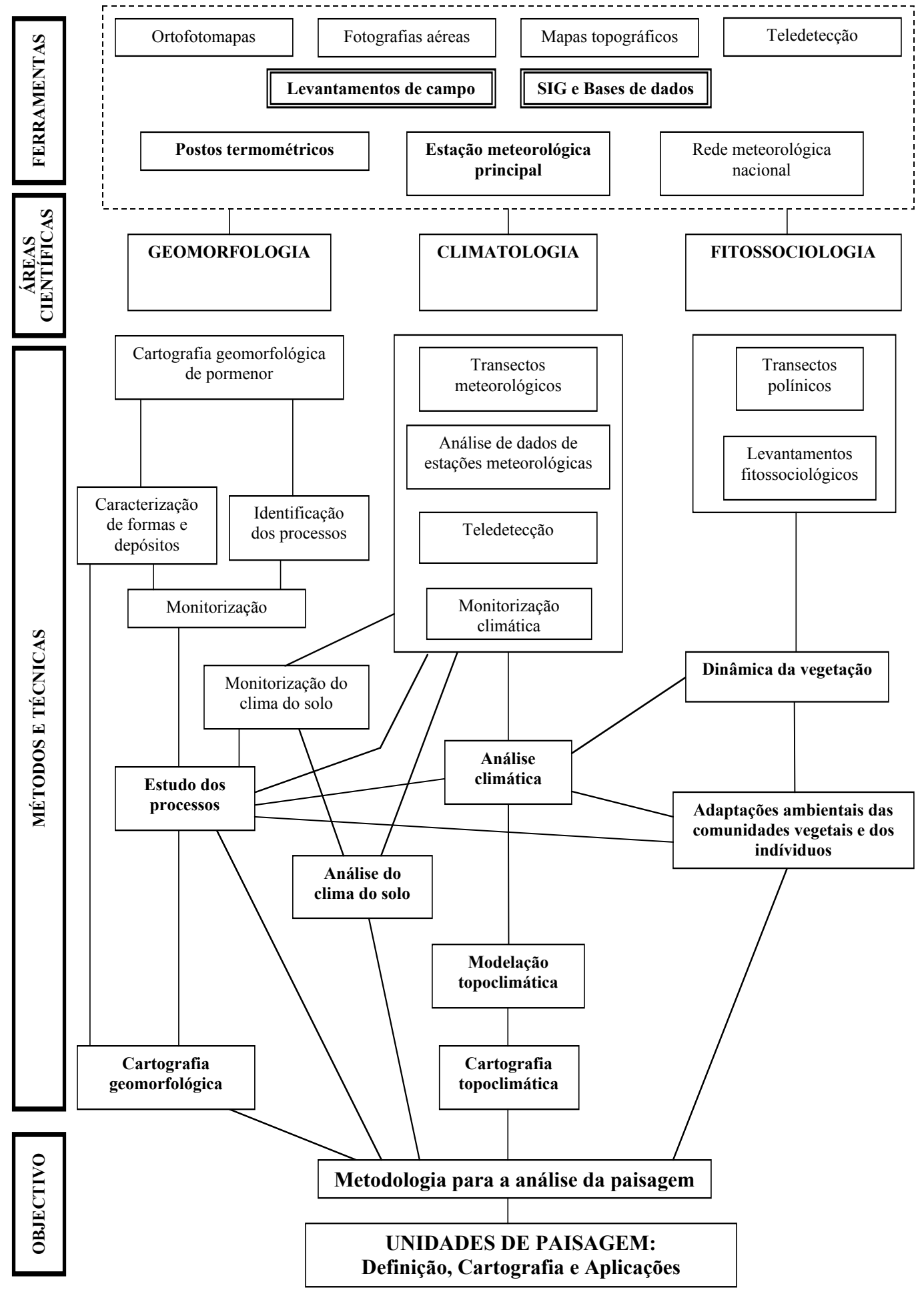

Fig. 2 - Organização geral da investigação no âmbito do projecto ESTRELA. Fig. 2 - General framework of the ESTRELA project. 
detalhe dos elementos a cartografar. Essa informação foi depois digitalizada e, com o auxílio de ortofotomapas digitais de grande escala, corrigido o posicionamento dos elementos cartografados. Os ortofotomapas foram também usados para cartografar diversos elementos cuja delimitação no campo seria difícil e morosa. É o caso da delimitação dos afloramentos de rocha nua e das áreas revestidas de areias graníticas, as quais têm consequências muito diversas na dinâmica geomorfológica e, obviamente, no revestimento vegetal.

Para melhor compreender a dinâmica dos planaltos superiores da Serra da Estrela, que constituem as áreas onde a intervenção humana é menos acentuada, foram efectuadas várias experiências de campo para a monitorização dos processos erosivos. Particular atenção foi dada aos processos hidro-eólicos, criogénicos e eólicos. A monitorização consistiu na instalação de linhas pintadas no solo (VIEIRA et al., 2002), grânulos pintados (movimento horizontal e vertical no solo), tubos para monitorização da corrasão, instalação de obstáculos ao movimento superficial e seguimento fotográfico de alguns sítios considerados de maior interesse. Foram também monitorizados os regimes térmicos do solo, da rocha e do ar em áreas-amostra da serra (VIEIRA et al. 2001b). Este procedimento permitiu estudar a dinâmica criogénica actual das áreas altas, aspecto que era quase totalmente desconhecido. A monitorização foi acompanhada pelo estudo sedimentológico de vários tipos de depósitos, particularmente os associados à dinâmica hidro-eólica e criogénica. Foi deste modo possível aprofundar o estudo dos processos que os originam.

\section{A análise climatológica}

O tempo atmosférico é, sem dúvida, uma realidade bem perceptível e o seu ritmo estacional constitui um dos aspectos fundamentais do ambiente físico. No entanto, no âmbito deste projecto, mais do que tentar determinar o papel directo do clima na caracterização da paisagem física, o que se procurou fazer foi a análise do quadro climático a diferentes escalas de maneira a individualizar determinados elementos ou parâmetros com consequências na dinâmica geomorfológica, na flora e na vegetação.

Definiram-se, assim, três escalas de análise no âmbito da Serra da Estrela: macroescala, mesoescala e microescala. No que se refere à macroescala, tentou-se delimitar as grandes unidades climáticas da serra, e o modo como se faz a transição entre estas e as das áreas envolventes. Para isso, além da utilização da bibliografia existente (Daveau et al., 1978; Daveau, 1985; Ventura, 1985; ANDRADE et al., 1992), fez-se a análise de dados da rede meteorológica nacional (IM e INAG) e de uma estação meteorológica instalada para o efeito no Alto da Torre (1993 m), e utilizou-se também a detecção remota. Entre outros aspectos, estudou-se a variação temporal e espacial dos vários elementos do clima (MorA et al., 2001), tendo-se efectuado diferentes tratamentos estatísticos e desenvolvido modelos, posteriormente integrados num Sistema de Informação Geográfica para obter a representação espacial das variáveis. Usaram-se ainda, 
para dias particulares, imagens de satélite Landsat TM que permitem realizar uma representação cartográfica relativamente fiável da vegetação, bem como obter informações acerca de outras variáveis importantes para o estudo dos microclimas, como as temperaturas e as respostas radiométricas das diferentes superfícies.

O estudo à mesoescala teve como suporte principal a instalação de 9 postos termométricos automáticos (VIEIRA et al., 2000; Mora et al., 2001), de modo a identificar os padrões térmicos de determinados lugares da serra em diferentes condições meteorológicas. Para melhorar a rede de monitorização, foram efectuadas, em dias escolhidos, medições itinerantes da temperatura, humidade e vento, acompanhadas pela monitorização térmica de elevada frequência em sítios com posição topográfica diferenciada. Este método permitiu analisar, entre outros aspectos, as condições de drenagem e acumulação de ar frio, responsáveis por fortes contrastes térmicos nocturnos nas áreas de montanha.

À microescala, estudaram-se particularmente as temperaturas do solo e da rocha e suas relações com a dinâmica geomorfológica (sobretudo a relacionada com o frio) e com a vegetação. Um dos aspectos mais interessantes, que se encontra ainda em estudo, é o da adaptação da vegetação crio-oromediterrânea à dinâmica geomorfológica. Para a monitorização da temperatura do solo e da rocha, desenvolveram-se dois sistemas de aquisição automática de dados com sondas termométricas a 1, 5, 10 e $15 \mathrm{~cm}$ de profundidade (VIEIRA et al., 2000). Os postos de monitorização de temperaturas do solo foram instalados no topo do Cântaro Gordo (1875 m) e na Fraga das Penas (1640 m), locais onde também foram registadas as temperaturas do ar. Próximo do cimo do Cântaro Gordo, foram instalados, em sectores verticais das vertentes norte e sul, dois postos de monitorização das temperaturas da rocha. O principal objectivo destes é permitir o estudo do regime térmico e das suas consequências na fragmentação da rocha. As temperaturas, no solo, como na rocha, têm sido registadas sincronicamente, em intervalos de 2 horas.

\section{O estudo da vegetação}

O estudo da vegetação foi também realizado a três escalas: macroescala, mesoescala e microescala. À macroescala, em que sobressaem os principais traços morfológicos da Serra da Estrela (planaltos, picos, vales e vertentes), a contribuição da vegetação para a diferenciação da paisagem é essencialmente fisionómica. Por isso, procedeu-se à divisão das formações vegetais nas seguintes classes: florestas, matos, áreas com vegetação herbácea, lagoas, e culturas, distinguindo-se também o substrato rochoso e os espaços construídos. Apesar do seu fraco significado botânico, essas classes são significativas num primeiro nível de análise da paisagem, e bastante importantes na influência exercida sobre a dinâmica geomorfológica e os climas locais. Para a elaboração da cartografia foram utilizadas fotografias aéreas a preto e branco, e ortofotomapas digitais em falsa cor. Um detalhado reconhecimento de campo foi fundamental para a boa qualidade da cartografia. 
À mesoescala, procurou-se fazer a delimitação cartográfica das unidades de vegetação tendo em conta a sua homogeneidade fitossociológica. Na análise da vegetação adoptou-se a metodologia da escola de Zurique-Montpellier (BRAUN-Blanquet, 1964; Westhoff e Van Der MaArel, 1973). Para a definição das unidades de vegetação foram utilisados os critérios de classificação de JANSEN et al. (1999), RIVAS-MARTínez et al. (2000) e JANSEN (2000, 2002). O modo como a delimitação das unidades de vegetação foi feita teve em conta a possibilidade de as cartografar à escala de 1:10.000. O levantamento cartográfico inicia-se com o reconhecimento sistemático da área de estudo e identificação das associações e de outras unidades de vegetação presentes. São então efectuados levantamentos de pormenor da vegetação nos locais mais significativos para cada classe identificada; só depois se procede à delimitação preliminar das unidades de vegetação numa base topográfica. Segue-se a observação da área a partir de um local afastado, mas que permita visualizar as várias unidades. Os seus limites são então definidos com maior rigor no mapa topográfico e em fotografias digitais. Posteriormente, durante a digitalização da informação em ambiente SIG, são usados ortofotomapas em falsa cor para aferir a delimitação das manchas cartografadas no campo.

À microescala corresponde um estudo detalhado em áreas de poucos metros quadrados. Esses levantamentos são elaborados de modo espacialmente descontínuo, e enquadram-se no âmbito de uma investigação fitossociológica mais ampla e aprofundada, que Jan Jansen vem desenvolvendo na Serra da Estrela. A fim de caracterizar a variabilidade interna das associações e tentar relacioná-la com factores geográficos, foi feito um levantamento de grande pormenor numa área com $44 \mathrm{~m}^{2}$, no topo do Cântaro Gordo. Este levantamento foi feito por uma equipa que incluíu botânicos, geomorfólogos e climatólogos, de modo a identificar no campo os possíveis factores condicionantes do desenvolvimento da vegetação. Estudaram-se duas associações típicas do Cântaro Gordo, a Lycopodio clavati-Juniperetum nanae cytisetosum oromediterranei (JANSEN, inédito) e a Sileno elegantis - Luzuletum caespitosae (JANSEN, inédito). Em relação à última, foi efectuada uma cartografia muito detalhada da distribuição dos indivíduos, com base numa quadrícula de $0,36 \mathrm{~m}^{2}$. Do ponto de vista geomorfológico, trata-se de uma área com terracettes, um tipo de modelado associado à alternância da congelação e fusão de gelo no solo, um dos fenómenos mais interessantes da morfogénese actual dos planaltos superiores. Ao mesmo tempo, realizaram-se cortes no terreno e foram recolhidas amostras de depósitos e rególitos para análise granulométrica.

\section{Integração das pesquisas sectoriais}

Com o objectivo de tentar integrar as pesquisas sectoriais, foram escolhidas áreas-amostra para um estudo interdisciplinar. No presente artigo vamo-nos servir da área-amostra do Covão Cimeiro - Cântaro Gordo, a fim de ilustrar o tipo de análise efectuada e os resultados que, por essa via, se podem obter (fig. 3 e 4). 
Fig. 3 - Transecto entre o Alto da Torre e a Fraga das Penas mostrando a localização das áreas de trabalho e da instrumentação para monitorização climática.

Fig. 3 -Cross-section from Alto da Torre to Fraga das Penas showing the study areas and the location of instruments for climate monitoring. 


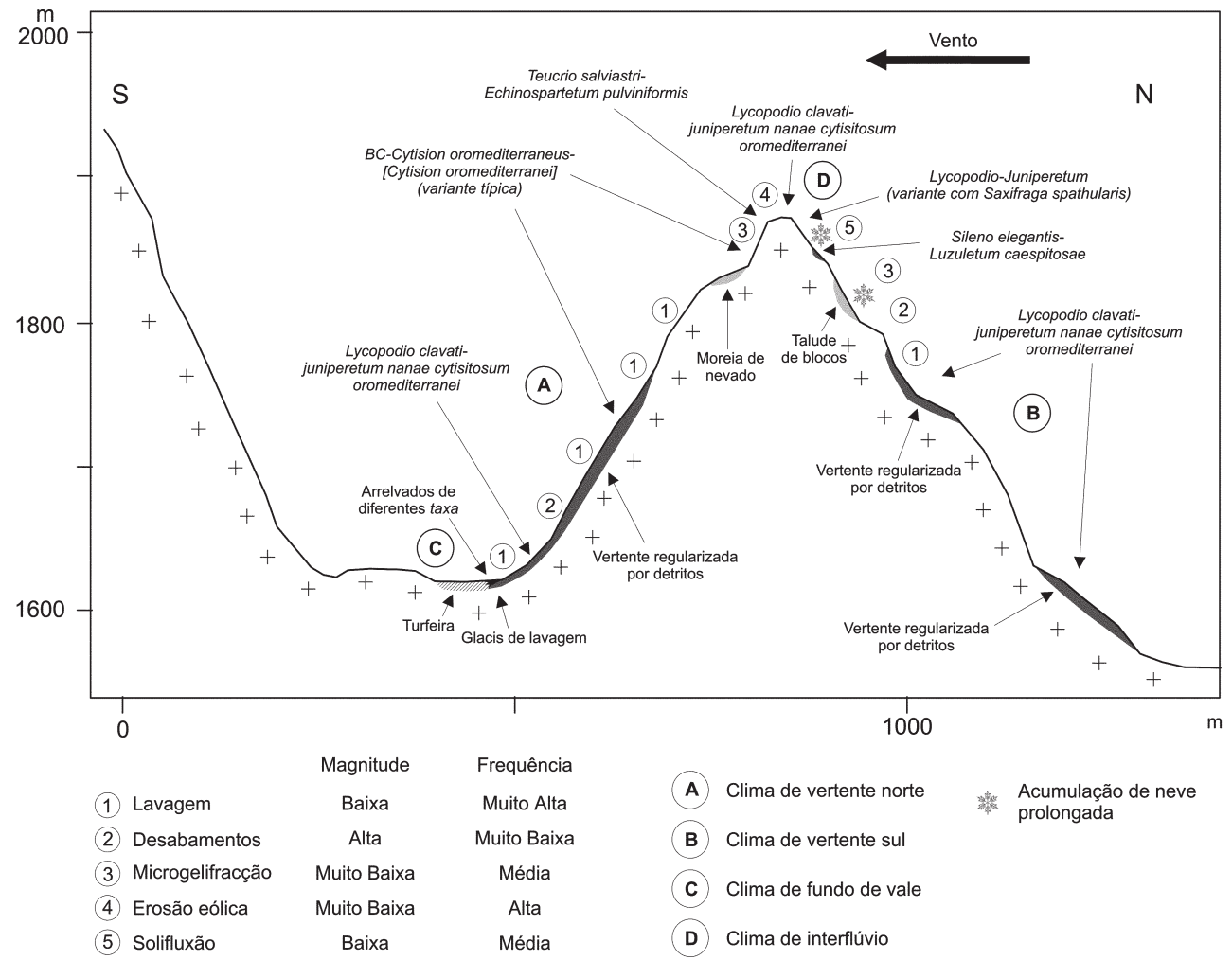

Fig. 4 - Transecto esquemático das principais características da paisagem na área de pormenor do Covão Cimeiro - Cântaro Gordo.

Fig. 4 -Cross-section showing the main characteristics of the landscape in the Covão Cimeiro - Cântaro Gordo study area.

O Cântaro Gordo é uma pequena crista, com uma forma próxima de um horn da morfologia alpina, orientada no sentido este-oeste, e culminando a 1875 $\mathrm{m}$ de altitude. Localiza-se a cerca de 1,5 km a nordeste do Alto da Torre, o ponto mais alto da Serra da Estrela (1993 m), contactando a sua vertente sul com o circo glaciário do Covão Cimeiro $(1614 \mathrm{~m})$, e a vertente norte com o vale glaciário da Candieira (1420 m). Apesar de os trabalhos se terem estendido a todo o circo glaciário do Covão Cimeiro, apenas apresentamos os dados referentes às duas vertentes do Cântaro Gordo, acima de $1600 \mathrm{~m}$ de altitude (fig. 4, 5 e 6).

No Cântaro Gordo, foram efectuados levantamentos geomorfológicos e das associações de vegetação à escala 1:10.000, assim como levantamentos fitossociológicos em locais-chave. Foram também instalados postos de monitorização das temperaturas do ar no topo, no Covão Cimeiro e no vale da Candieira, registando dados em intervalos de 2 horas. A temperatura do solo foi monitorizada 


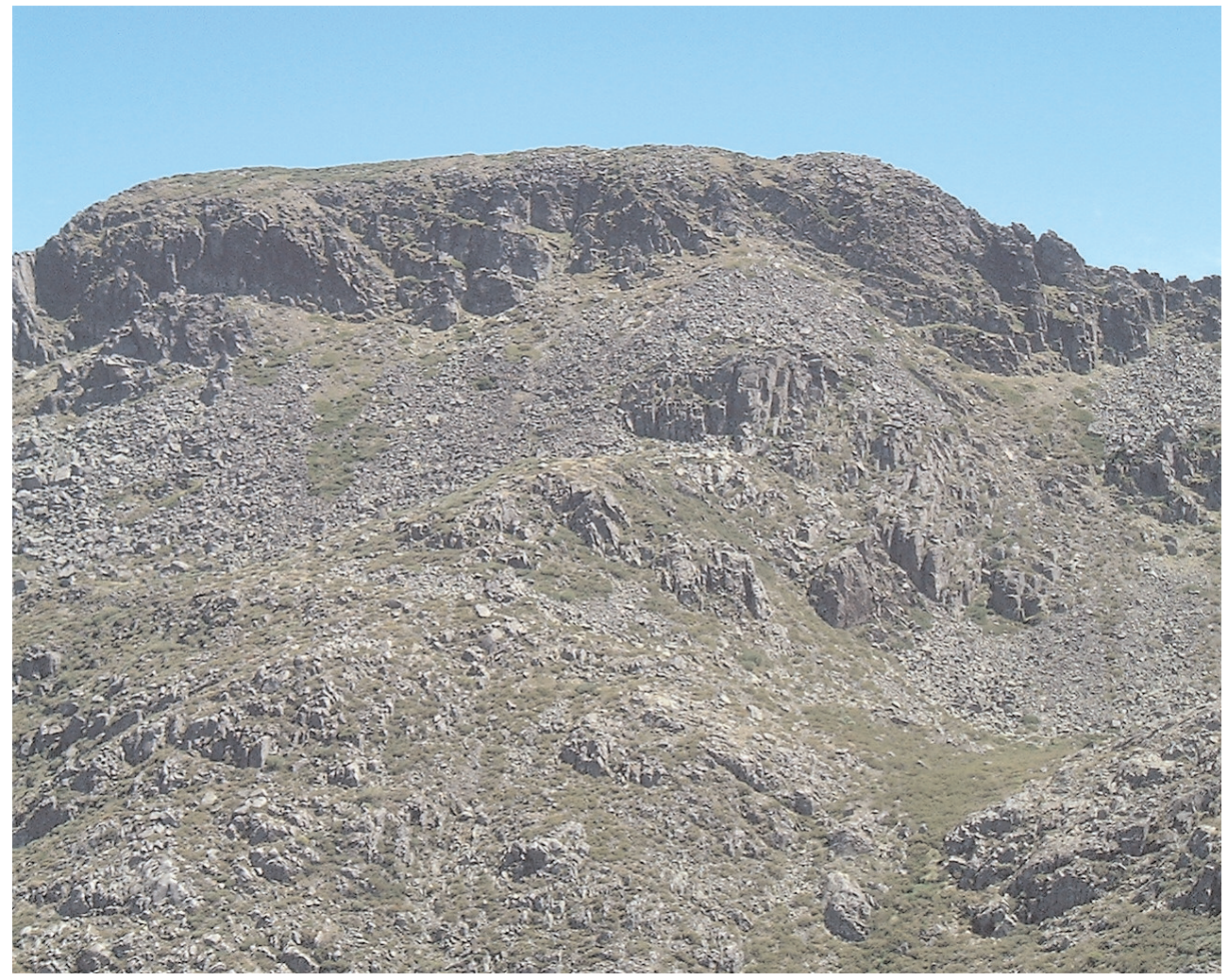

Fig. 5 - Aspecto do sector superior da vertente norte do Cântaro Gordo. Cornija periglaciária, ainda activa - abaixo dela, depósitos de vertente herdados e actuais. A cobertura vegetal é essencialmente comandada pela ocorrência de depósitos mais finos.

Fig. 5 - The north slope of the Cântaro Gordo. Active periglacial free-face and present-day and relict rockfall deposits. Vegetation cover depends mainly on the availability of fine material.

no topo do Cântaro Gordo em quatro níveis, entre 1 e $15 \mathrm{~cm}$ de profundidade, e a temperatura da rocha foi monitorizada nas duas vertentes, a $1870 \mathrm{~m}$ de altitude, também entre 1 e $15 \mathrm{~cm}$ de profundidade, em afloramentos verticais de granito. Numa campanha de cerca de uma semana de duração, no Verão de 2000, foram medidas as temperaturas do ar no topo, e nas vertentes norte e sul, com intervalos de 5 minutos, de modo a conhecer o seu comportamento em situações de estabilidade atmosférica. Ao mesmo tempo efectuaram-se medições itinerantes, com registo da temperatura e humidade do ar, velocidade e rumo do vento, bem como elementos do balanço radiativo (radiação de onda curta e 

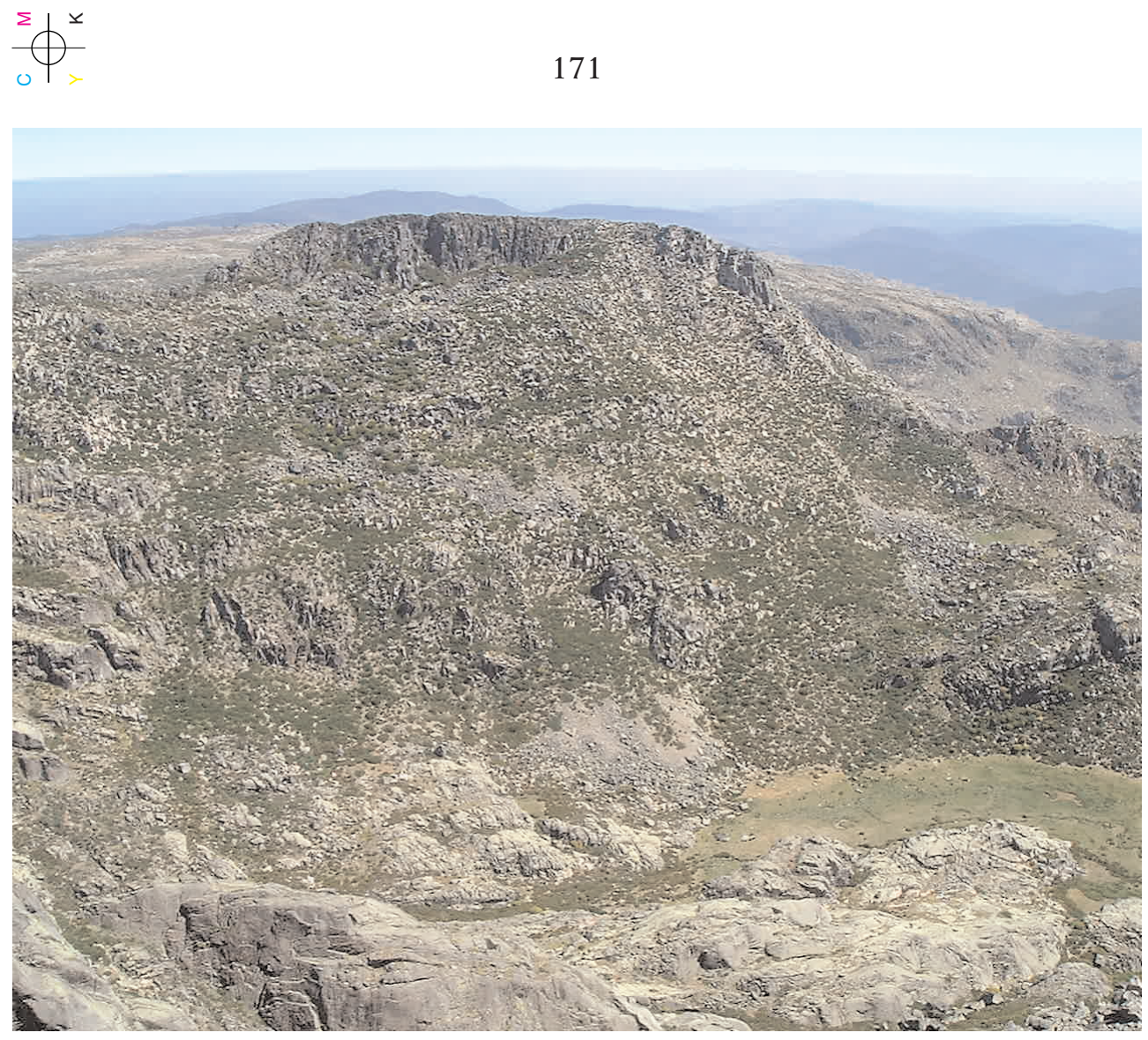

Fig. 6 - Aspecto da vertente sul do Cântaro Gordo. Notar na base da vertente o fundo do circo glaciário do Covão Cimeiro, onde se desenvolve uma turfeira. O topo da vertente apresenta uma cornija periglaciária, na base da qual se encontra uma acumulação herdada de blocos de grande dimensão (moreia de nevado), seguindo-se uma vertente regularizada por detritos.

Fig. 6 - The south slope of Cântaro Gordo. At the bottom of the slope note the overdeepening of the Covão Cimeiro glacial cirque with a peatbog. The upper part of the slope presents a periglacial free-face and a small protalus rampart. Most of the slope is debris-mantled.

infravermelha, ascendente e descendente). A modelação da insolação num software de Sistema de Informação Geográfica ajudou a caracterizar as condições climáticas do ar, do solo e as condições de desenvolvimento da vegetação. A área foi visitada várias vezes em condições meteorológicas contrastadas e em diferentes estações do ano, de modo a observar directamente a dinâmica geomorfológica, da vegetação e do clima. 
A figura 4 ilustra as principais características da área do Cântaro Gordo, nomeadamente a geomorfologia, vegetação e clima local. Estes três aspectos encontram-se fortemente relacionados, mesmo considerando a existência de um quarto factor na dinâmica da paisagem, a influência antrópica.

A forma das vertentes graníticas do Cântaro Gordo e o fundo mal drenado do Covão Cimeiro resultam, na sua maior parte, da acção erosiva dos glaciares plistocénicos; e os sectores mais elevados do interflúvio, resultam principalmente de uma dinâmica periglaciária também herdada. A tectónica, além do seu papel passivo na fracturação, pode ter tido também influência no desalojamento de blocos, particularmente num talude presente na vertente norte. A meteorização das rochas posterior à glaciação, bem como a remobilização de material desagregado originaram a regularização dos dois terços inferiores da vertente sul e dos sectores menos declivosos da vertente norte. É fundamentalmente esta paleodinâmica que determina a localização actual dos afloramentos de rocha nua e das áreas cobertas com depósito, duas condições litológicas obviamente muito distintas no que concerne o desenvolvimento da vegetação. A dinâmica geomorfológica actual caracteriza-se pelo predomínio da escorrência superficial, responsável pela formação de pequenos glacis de acumulação no sopé das vertentes. Em alguns sectores da vertente norte, verifica-se a congelação sazonal do solo, o que dá origem à ocorrência de solifluxão. Outros processos activos, são a erosão eólica (corrasão) e os desabamentos. $\mathrm{Na}$ figura 4 representa-se uma estimativa da magnitude e frequência dos diferentes pro-cessos activos.

Nesta escala de análise, a diferenciação espacial do clima é sobretudo marcada pelas características da topografia. Foram assim identificados quatro tipos de clima local: 1) o clima de interflúvio, caracterizado por uma forte exposição ao vento de todos os quadrantes, temperaturas baixas devido à altitude, e amplitude térmica diária moderada; 2) o clima de fundo de vale, mais abrigado dos ventos fortes, mas com influência de ventos locais induzidos por causas térmicas, elevada amplitude térmica diária, particularmente nos episódios com céu limpo, sendo então as temperaturas mínimas muito baixas (formação de um lago de ar frio) (Mora et al., 2001), e as máximas relativamente elevadas (reflexão da radiação solar e emissão de radiação infra-vermelha pelas vertentes); 3) o clima de vertente sul, relativamente abrigado do vento dominante, mas com elevada amplitude térmica diária, sendo especialmente marcantes as temperaturas máximas, devido à forte insolação; 4) o clima de vertente norte, exposto aos ventos dominantes e sempre relativamente frios de norte, e marcado por uma fraca insolação, particularmente no Inverno, e por uma moderada amplitude térmica no Verão, sendo fraca no Inverno. A modelação da insolação revela que, durante o Verão, as diferenças entre as vertentes norte e sul são fracas (no solstício, ambas recebem cerca de 12 horas de radiação solar directa); porém no Inverno, as diferenças são muito significativas (no solstício, a vertente norte não recebe radiação solar directa, mas a exposta asul, recebe cerca de 7 a 8 horas de sol). É importante notar que durante as situações de céu 
limpo com estabilidade atmosférica, a drenagem do ar frio ao longo da vertentes origina um lago de ar frio nos fundos de vale, e uma cintura de temperaturas mais elevadas a meia-vertente. A posição desta, ainda não determinada, deverá ser distinta nas vertentes norte e sul, particularmente devido ao diferente comando, mas também a diferenças topográficas. Um outro elemento climático, que condiciona a vegetação e a dinâmica geomorfológica, é a presença de neve no solo, que permanece durante um período mais longo na vertente norte do que na vertente sul.

No que se refere à vegetação, apesar de apenas surgirem 6 unidades no esquema da figura 4, no levantamento cartográfico elaborado foram identificadas 21 unidades. A associação dominante no perfil estudado é a Lycopodio clavati-juniperetum nanae cytisetosum oromediterranei, que corresponde a uma associação climácica em condições mesófilas, e que traduz essencialmente, na Serra da Estrela, as condições climáticas regionais a estas altitudes. Ela surge, por isso, nas duas vertentes, e mesmo no topo, embora com diferenças de porte, devido a constrangimentos climáticos, como o vento e a formação de sincelos. A existência da associação $B C$ - Cytisus oromediterraneus - [Cytision oromediterranei] (variante com Erica arborea, segundo JANSEN, 1994) na metade superior da vertente sul, deve-se a um incêndio recente, que terá destruído a primeira associação, originando uma comunidade basal (BC - Basal Community segundo KoPeCKÝ e HeJnÝ, 1978) muito degradada. Aliás, os incêndios provocados pelos pastores constituem um factor muito importante a considerar na história, dinâmica e estrutura da paisagem actual. A sua acção é especialmente marcante nas vertentes expostas a sul; o último em data, ocorrido no Verão de 2001, queimou por completo a vegetação da vertente sul do Cântaro Gordo, que tinha sido objecto de estudo no âmbito deste projecto.

Algumas associações são particularmente interessantes para a identificação das condições ecológicas locais. Assim, a ocorrência da associação Teucrio salviastri-Echinospartetum pulviniformis na vertente sul, próximo do topo do Cântaro Gordo, ilustra condições de secura muito acentuadas, induzidas pela forte insolação e pelo vento. Por sua vez, a associação Sileno elegantis - Luzuletum caespitosae presente no sector superior da vertente norte, onde existe material não coerente, reflecte condições de frio intenso, e de forte exposição ao vento dominante. $\mathrm{O}$ frio intenso está bem patente na morfogénese actual, com a ocorrência de solifluxão, que dá origem às terracettes. Finalmente, no sector exposto a norte do topo do Cântaro Gordo, encontramos uma variante da associação Lycopodio-Juniperetum (com Saxifraga spathularis), que estará relacionada com condições mais húmidas do que a variante típica, e provavelmente com a presença prolongada de neve no solo.

\section{Remate}

O desnível entre os depressões circundantes e os cimos da Serra da Estrela chega a atingir $1.500 \mathrm{~m}$, de modo que a altitude surge como o principal factor 
da diferenciação ecológica da montanha, à escala regional. As diferenças de altitude traduzem-se em diferentes condições climáticas e estas reflectem-se também nas características da flora e da vegetação. Segundo RIVAS-MARTínez (1981) podem considerar-se três andares termoclimáticos na Serra da Estrela: o andar mesomediterrâneo, até à altitude de cerca de 900 m; o andar supramediterrâneo, de 900 a $1650 \mathrm{~m}$; e o andar oromediterrâneo, acima de $1650 \mathrm{~m}$.

Uma análise polínica já antiga (Romariz, 1950) efectuada em turfeiras da Lagoa Comprida e da Lagoa dos Covões, detectou a existência de pólenes de Pinheiro silvestre (Pinus sylvestris), Vidoeiro (Betula sp.) e Teixo (Taxus baccata), e esse facto poderia significar, segundo PinTo DA Silva e Teles (1986, pp. 33-34), que os cimos da serra teriam sido ocupados por essas espécies florestais depois do desaparecimento dos glaciares. No entanto, os detalhados estudos polínicos dos sedimentos lacustres do Charco da Candeeira, situados a $1400 \mathrm{~m}$ de altitude, no sopé setentrional do Cântaro Gordo, e de mais sete sondagens situadas entre 1600 m e 1845 m de altitude (VAN DER KNAAP e VAN LeEuWEn, 1994, 1995, 1997) indicam que a floresta nunca terá ultrapassado, nos tempos pós-glaciários, a altitude de $1700-1800 \mathrm{~m}$, e seria constituída essencialmente por carvalhos. Durante o Óptimo Climático do Holocénico (Boreal), a vegetação a $1770 \mathrm{~m}$ de altitude (localização de um dos perfis polínicos estudados) parece representar uma "zona de tensão» no limite superior da floresta (VAN DER KNAAP e VAN LEEUWEN, 1997, p. 274). Em qualquer caso, no andar oromediterrâneo actual não existem comunidades florestais, mas antes mosaicos de vegetação arbustiva e herbácea, nomeadamente (Pinto da Silva e Teles, 1986; Jansen et al., 1997): zimbrais (Lycopodium-Juniperetum), urzais (Potentillo-Callunetum), cervunais (Galio-Nardetum, Campanulo-Festucetum henriquesii) e arrelvados (Arenario-Cerastietum, Jasiono-Minuartietum).

$\mathrm{Na}$ Serra da Estrela, a litologia do substrato rochoso não parece constituir um factor de primeira ordem na distribuição do revestimento vegetal, a não ser se tomarmos em conjunto, por um lado, as partes mais altas da serra, de natureza granítica, e por outro lado, as áreas envolventes, sobretudo dos lados sudoeste e nordeste, que são de constituição metassedimentar. Todavia, as paisagens graníticas estão longe de ser uniformes ou monótonas, apresentando pelo contrário uma acentuada diversidade morfológica que se impõe ao primeiro golpe de vista, quer nas áreas não glaciadas, em que domina uma paisagem de alteração química e bioquímica, quer nas áreas outrora cobertas pelos gelos, onde se encontra um cortejo de formas típicas ligadas à morfogénese glaciária. Estas formas salientam-se na paisagem actual não só pela sua fisionomia, mas também porque criam condições ecológicas que se reflectem na flora e na vegetação, através das variações de declive, da orientação das suas vertentes ao sol e aos ventos, da existência ou não de rególitos ou de depósitos, da granulometria destes. Por isso, além dos mosaicos de vegetação arbustiva e herbácea mencionados, no andar oromediterrâneo (e também no supramediterrâneo) existe uma vegetação especializada em meios por vezes pouco extensos mas contrastados, podendo falar-se de uma vegetação do substrato rochoso, de uma 
vegetação das cascalheiras de vertente (ligadas a maior parte delas à gelifracção herdada), vegetação de turfeiras, charcos, nascentes e pequenas lagoas. A dinâmica actual, hídrica, eólica, hidro-eólica ou criogénica, reflecte também a geomorfologia herdada mas cria ela própria condições diversas, que se traduzem nas características do revestimento vegetal.

Segundo VAN DER KNAAP e VAN LEeUwen (1994), os primeiros indícios da intervenção antrópica na Serra da Estrela remontam a 7635 anos B.P., tornando-se dominante, isto é, sobrepondo-se ao sinal climático, a partir de 5585 anos B.P. (idades não calibradas). Seguiram-se vários ciclos de desflorestação, que ganharam altitudes cada vez mais elevadas, e o último, que se situará entre 845 e 340 anos B.P., conduziu à paisagem actual, não florestal. Nos andares meso e supramediterrâneo, a intervenção antrópica foi de tal modo intensa que a vegetação natural, nomeadamente a vegetação arbórea, é hoje praticamente inexistente. Os matos presentes actualmente no andar supramediterrâneo, nomeadamente os giestais de Cytisus multifloris e os sargaçais de Halimium lasianthum subsp. alyssoides ocupam áreas muito degradadas pelo homem, devido sobretudo à cultura do centeio, o que explicará a sua grande pobreza florística. Pelo contrário, os urzais de Erica australis subsp. aragonensis, não são normalmente sujeitos a arroteamentos, sendo afectados apenas pelo pastoreio e pelos incêndios, o que explicará a sua maior riqueza florística (PINTO DA SiLva e TELEs, 1986, p. 31). O andar oromediterrâneo foi o menos atingido pelas actividades humanas, mas os incêndios e o pastoreio têm contribuído para importantes modificações na vegetação natural. Os zimbrais são protegidos pelo homem e poupados pelo gado, mas são muito sensíveis aos incêndios. Os cervunais, nomeadamente o Galio-Nardetum são apascentados, ano após ano, pelo gado transumante. Em situação de sobrepastoreio, que favorece a erosão hídrica, dá-se uma degradação do cervunal, o qual origina frequentemente arrelvados que crescem num saibro grosseiro, empobrecido nos elementos minerais finos, o Arenario-Cerastietum ramosissimi (Pinto DA Silva e Teles, 1986, pp. 39-40).

As paisagens actuais da Serra da Estrela traduzem uma evolução muito longa, que remonta ao Paleozóico (mais de 250 milhões de anos), a era em que se definiu a natureza litológica e a estrutura do substrato rochoso. As superfícies de aplanamento, que determinam a fisionomia dos interflúvios, são, no essencial, anteriores ao Miocénico (mais de 25 milhões de anos). A tectónica que originou o levantamento da montanha em relação aos planaltos periféricos e o grande encaixe da drenagem, vai essencialmente do Miocénico médio (15 milhões de anos) até à actualidade. A morfogénese responsável pelas formas de relevo glaciárias e periglaciárias dos planaltos superiores e dos grandes vales divergentes datam do Plistocénico Superior (limite inferior ainda desconhecido, mas limite superior datando do Dryas Recente, mais ou menos há 12.000 anos). Depois da glaciação, a vegetação pioneira, no Charco da Candieira, a $1400 \mathrm{~m}$ de altitude, surgiu apenas na primeira metade do Bölling (há pouco mais de 14.500 anos) e a floresta de Quercus substituíu uma charneca aberta a esta 
altitude apenas no início do Holocénico (há cerca de 11.000 anos). Desde há cerca de 6.000 anos até à actualidade, a acção antrópica, através do fogo, do pastoreio e da agricultura tornou-se o factor dominante da evolução da flora e da vegetação.

Sem esta dimensão temporal da evolução da paisagem não é possível entender a paisagem actual da Serra da Estrela. Mas essa evolução temporal traduz-se de maneira diferente conforme a escala espacial que se considera. Por isso, é essencial no estudo das paisagens de um determinado território definir diferentes escalas de análise. No caso do projecto ESTRELA, foram definidas três escalas: 1) a macroescala, ou escala regional, em que sobressaem os andares bioclimáticos, as principais formas do relevo e os grandes contrastes de exposição das vertentes; 2) a mesoescala, onde melhor se manifestam os contrastes de rocha sã ou alterada, a espessura do manto de alteração ou dos sedimentos, as condições de drenagem, os topoclimas e as unidades de vegetação; 3) a microescala, em que se pode analisar os processos geomorfológicos actuais, os microclimas (nomeadamente, temperatura do solo e da rocha), e a variabilidade interna das unidades de vegetação. A cada escala espacial de análise, correspondem critérios diferentes da segmentação da paisagem. Um dos objectivos do projecto ESTRELA é o de definir esses critérios, nomeadamente no andar oromediterrâneo da Serra da Estrela.

\section{AGRADECIMENTO}

Este trabalho enquadra-se no âmbito das actividades do Projecto «Processos Geomorfológicos e Biofísicos e Unidades de Paisagem em Ambiente de Montanha Mediterrânea. Aplicação à Serra da Estrela - ESTRELA» (PRAXIS/ C/TE/11153/1998), financiado pela Fundação para a Ciência e a Tecnologia.

\section{BIBLIOGRAFIA}

Andrade, E.; Mora, C.; Neves, M.; Vieira, G. (1992) - Desportos de Inverno na Serra da Estrela. Contribuição para o estudo da sua viabilidade, Finisterra, XXVII (53-54), C.E.G., Lisboa: 187-193.

Beroutchachvili, N.; Bertrand, G. (1978) - Le Géosystème ou «Système territorial naturel». Rev. Géogr. Pyr. Sud-Ouest, 49 (2): 167-180.

Bertrand, C.; Bertrand, G. (1986) - L'élément et le système. Rev. Géogr. Pyr. Sud-Ouest, 57 (3): 291-312.

Bertrand, G. (1968) - Paysage et géographie physique globale. Esquisse méthodologique. Rev. Géogr. Pyr. Sud-Ouest, 19 (3): 249-272.

Bertrand, G. (1972) - Les structures naturelles de l'espace géographique. L'exemple des Montagnes Cantabriques centrales (nord-ouest de l'Espagne). Rev. Géogr. Pyr. Sud-Ouest, 43 (2): 175-206.

Braun-Blanquet, J. (1964) - Pflanzensoziologie. 3. Aufl., Wien-New York, 632 pp. 
CailleuX, A.; Tricart, J. (1956) - Le problème de la classification des faits géographiques. Annales de Géographie, LXV: 162-186.

CARCenac-Suffert, C. (1978) - Les géosystèmes du bassin d'Arques (Corbières, Aude). Rev. Géogr. Pyr. Sud-Ouest, 49 (2): 199-220.

Daveau, S. (1971) - La glaciation de la Serra da Estrela. Finisterra - Revista Portuguesa de Geografia, VI (11): 5-40.

Daveau, S. (1985) - Mapas climáticos de Portugal. Nevoeiro e nebulosidade. Contrastes térmicos, Memórias do C.E.G., 7, Lisboa.

Daveau., S.; Coelho, C.; Costa, V. G. e Carvalho, L. (1977) - Répartition et rythme des précipitations au Portugal. Memórias do C.E.G., 3, Lisboa.

Forman, R. T. T.; Godron, M. (1986) - Landscape Ecology. J. Wiley, N. Iorque, 619 pp.

Herail, G.; Hubschman, J. (1978) - Essai de cartographie intégrée d'un espace forestier: la forêt de Bouconne. Rev. Géogr. Pyr. Sud-Ouest, 49 (2): 221-238.

Huggett, R. J. (1995) - Geoecology. An evolutionary approach. Routledge, Londres, 320 pp.

JANSEN, J. (1994) - Stands of Cytisus oromediterraneus in the Serra da Estrela, with some remarks on the habitat of the Bluethroat (Luscinia svecica cyanecula). In: II seminário técnico conservação da natureza na Serra da Estrela, Manteigas: 23-45.

JANSEN, J. (2000) - A preliminary survey of the vegetation of the Serra da Estrela. III Encontro de Fitossociologia. Escola Superior Agrária de Castelo Branco, 17-20 de Julho de 2000. Livro de Resumos, p. 32.

Jansen, J. (2002) - Guia geobotânico da Serra da Estrela. Instituto da Conservação da Natureza. Lisboa (no prelo).

Jansen, J; Rego, F; Gonçalves, F. e Silveira, S. (1997) - Fire, a landscape shaping element in the Serra da Estrela, Portugal. NNA-Berichte, 10(5): 150-161.

Jansen, J.; Rivas-Martinez, S. e Westhoff, V (1999) - Oromediterranean hedgehog, broom, and dwarfjuniper scrub (class: Pino-Juniperetea Rivas-Martínez 1964) in the Serra da Estrela. 2. Encontro ALFA de Fitossociologia. A Fitossociologia na Gestão de Espaços Naturais. ALFA, CEF, Universidade de Lisboa, p. 29.

KoPeCKÝ, K. e S. HeJnÝ (1978)-Die Anwendung einer deduktiven Methode syntaxonomischer Klassifikation bei der Bearbeitung der strassenbegleitenden Pflanzengesellschaften Nordostböhmens, Vegetatio, 36: 36-51.

Mora, C.; Vieira, G.; Alcoforado, M. J. (2001) - Daily minimum air temperatures in Serra da Estrela, Portugal, Finisterra. Revista Portuguesa de Geografia, XXXVI (71): 49-59.

Pinto da Silva, A.R. e Teles, A.N. (1986) - A flora e a vegetação da Serra da Estrela. Colecção Parques Naturais, 7, 2. ${ }^{\mathrm{a}}$ ed., ICN, Lisboa: 3-52.

RichaRd, J.-F. (1975) - Paysages, Écosystèmes, Environnement: une approche géographique. L'Espace Géographique, 2: 81-92.

Rimbert, S. (1973) - Approches des Paysages. L’Espace Géographique, 3: 233-241.

Rivas-Martínez, S.; Aguiar, C; Costa, J.C.; Costa, M.; Jansen, J.; Ladero, M.; Lousã, M. e Pinto Gomes, C. (2000) - Dados sobre a vegetação da Serra da Estrela. Guia do itinerário dos III Encontros de Fitossociologia. Quercetea, 2: 3-63. 
Rougerie, G. (1969) - Géographie des Paysages. «Que Sais-Je?», n. ${ }^{\circ}$ 1362, Paris, 128 pp.

SALA, M. (1982/83) - Geoecología del paisage en el macizo litoral catalán. Revista de Geografia, XVI-XVII: 23-45.

TRICART, J. (1994) - L'Écogéographie des espaces ruraux. Nathan, Paris, 187 pp.

Troll, C. (1939) -Luftbildplan und ökologische Bodenforschung. Zeitschrift der Gesellschaft für Erdkunde, Berlim: 241-298.

Troll, C. (1971) - Landscape Ecology (Geoecology) and Biogeocenology - A Terminological Study. Geoforum, 8: 43-46.

Turner, M. G. (1989) - Landscape ecology: the effect of pattern on process. Annual Review of Ecology and Systematics, 20: 171-197.

VAN DER KNAAP, W.O; VAN LEEUWEN, J.F.N., 1994: Holocene vegetation, human impact, and climatic change in the Serra da Estrela, Portugal. In: LotTer \& Ammann (eds.): Festschrift Gerhard Lang. Diss. Bot. 234: 497-535.

VAN DER KNAAP, W. O.; VAN LeEUWEN, J. F. N. (1995) - Holocene vegetation succession and degradation as responses to climatic change and human activity in the Serra da Estrela, Portugal. Rev. Paleobot. Palynol., 60: 25-129.

VAN DeR KnaAP, W. O.; VAn Leeuwen, J. F. N. (1997) - Late Glacial and Early Holocene vegetation succession, altitudinal vegetation zonation, and climate change in the Serra da Estrela. Review of Paleobotany and Palynology, 97: 239-285.

Ventura, J. E. (1985) - Temperaturas máximas e mínimas em Portugal Continental. Tentativa de representação cartográfica, Relatório L.A.G.F., CEG, Lisboa, 28.

Vieira, G. T.; Mora, C.; Ramos, M. (2000) - Registadores automáticos de baixo-custo para a monitorização de temperaturas do ar, da rocha e do solo, Finisterra-Revista Portuguesa de Geografia, XXXV (69):139-148.

Vieira, G.; Ferreira, A. B.; Mycielska-Dowgiallo, E.; Woronko, B.; Olszak, I. (2001a) Thermoluminescence dating of fluvioglacial sediments (Serra da Estrela, Portugal). In Actas $V$ Reunião do Quaternário Ibérico / I Congresso do Quaternário dos Países de Línguas Ibéricas, Lisboa: $85-88$.

Vieira, G. T.; Mora, C.; Ramos, M. (2001b) - Observações acerca das temperaturas do ar e do solo na Serra da Estrela (Portugal), Periglaciarismo en montaña y altas latitudes, E. Serrano (ed.) (no prelo).

Vieira, G.; Mora, C.; Gouveia, M. M. (2002) - Oblique rainfall and contemporary geomorphological dynamics (Serra da Estrela, Portugal), Hydrological Processes (no prelo).

Westhoff, V. e Van der MaArel, E. (1973) - The Braun-Blanquet approach. In R. M. WhitTaker (ed.) - Ordination and classification of vegetation. Handbook of Vegetation Science, The Hague: 617-726. 